University of Gloucestershire, U.K. and Central Queensland University, Australia

\author{
Nigel McLoughlin and Donna Lee Brien
}

\title{
Creativity: Cognitive, social and cultural perspectives
}

Historically, the study of creativity has been undertaken from a great many perspectives. These include practice-based enquiry into the creative arts, studies of the creative process using auto-ethnographic methods, studies of creative individuals to investigate and outline creative traits, research which identifies the conditions which promote and inhibit creativity, creativity as a socio-cultural process, creativity as a cognitive process and the neuropsychology of creativity. In recent years, the term 'creativity' has become a buzzword in practically every sector of public life and many who teach and research within the creative disciplines in higher education have become increasingly sensitive to the rise of the terms 'creative' and 'creativity' as important and overarching themes within our universities. As both a concept and as a term, creativity has far-reaching appeal but, with this currency and popularity, there is a danger that the term's very meaning may become eroded. With this in mind, this special issue of TEXT offers an opportunity to refocus on creativity as a concept and a process. It also reflects a conscious effort to reclaim creativity and the creative process as something worthy of study, research and academic attention both within the creative arts disciplines and outside; through investigations in reflective practice and through interdisciplinary engagement with the crossing points offered by other disciplines which afford new perspectives on the study of creativity withinthose arts.

In conceiving this special issue of TEXT, one of our prime aims has been to respond to the challenges faced by researchers concerned with creativity today by creating a space wherein aspects of an interdisciplinary conversation about creativity that is grounded in the creative arts might take place. Many have become interested in analyzing creativity as a cognitive process and as a process of social and cultural interactions. In terms of the creative arts, neuroscientists have begun to investigate the neural processes related to artistic creativity within visual, musical and verbal arts. Cognitive psychologists and educational psychologists are not only researching creativity from those perspectives but are also incorporating ideas from the arts into their approaches. Those interested in innovation in the business world are becoming interested in how the creative process can be facilitated, and are also looking to creative arts disciplines for guidelines and guidance. Inside the creative arts, many researchers are also becoming increasingly aware of the work on creativity from outside their own disciplines, leading to many reaching out to other paradigms in order to embrace more interdisciplinary in their understanding of what creativity means for them both in terms of process and in terms of their own creative practice. Yet, unless in a specified interdisciplinary project, these different fields of research rarely if ever communicate directly to share ideas or collaborate on projects. 
This special issue, therefore, seeks to define and investigate creativity as a concept and mode of practice from a variety of disciplinary perspectives that all focus on, or around, the creative arts. In doing so, it brings together diverse viewpoints, knowledge bases, approaches and experience to give an overview of contemporary thought and practice related to the study of creativity, with the overarching thought that this may prompt further scholarship in this area. In our call for articles for this issue, therefore, we invited creative artists and researchers, cognitive psychologists, neuroscientists, educational researchers and others involved in developing and supporting research in creativity to contribute, and we were not disappointed by the response. We also invited authors from the UK, USA as well as Australasia and elsewhere, to test and explore similarities and differences in approach and conceptualisation across these two geographical areas.

Chris Morgan's paper reports the results of a research project which explores the views of university academics in the creative arts with regard to how creativity is conceptualized within their disciplines and what impact that conceptualization has on how their creative discipline is taught. Moving from the general to the specific, Jen Webb explores how poetry generates knowledge. Speculating on what that knowledge might be and relating it to the social conception of creativity, Webb also examines how the concept of creativity has changed over time and examines the standing of the current manifestation.

Outlining a quite different methodological approach, Steven Pace identifies and examines research methods in creative subjects that may be drawn from social science paradigms. Pace focuses on autoethnographic and grounded theory approaches in order to demonstrate how both may be deployed as discrete or combined methodologies to yield a framework for investigating practice-led research in the arts. From a very different disciplinary outlook but providing a similarly valuable framework, Arne Deitrich offers a broad survey of what neuroscience and cognitive psychology can tell us in regard to the neuropsychological mechanisms that may underlie the creative processes related to insight. The article takes the complex models and mechanisms, strips them of their jargon and presents them in straightforward terms.

Maria Engberg and David Prater's paper examines the idea that 'flash points' of creative realization can be pedagogically useful in fostering sophisticated critical and creative viewpoints among students in relation to writing in digital media. Derek Pigrum outlines his theory of transitional notation and analyses its relation to the creation of and encoding of potential space in creative endeavours. He contextualizes his theory in relation to the 'semiotic chora' and the notion of the 'good enough mother' in order to investigate ways that transitional notation and potential space may offer new pedagogical directions in creative fields. John Baer's paper puts the case for domain specificity in creativity by examining the research findings that support this position and analyzing the ecological validity of these findings with regard to the creative traits observed in the population.

Together, these articles provide, we believe, a variety of valuable perspectives on various facets of creativity and the creative process, which will progress 
interdisciplinary conversations about the practice and pedagogy of creative disciplines and the study of creativity as a cognitive, social and cultural phenomenon For those new to such areas of discussion in relation to the study of creativity, we hope this special issue provides an introduction to the range of discussions and debates that are taking place. For those more cognisant with the subtleties of these deliberations in their own disciplines, we hope it offers stimulation for considering interdisciplinary engagement with these questions. For all readers, we believe this collection provides an opportunity to open up further discussion and inspire more research regarding the nature of the creative process and what creativity means to creative artists in both practice and as members of the wider society.

In compiling this issue, we have found working with our various contributors and each other very interesting. We would like to extend our sincere thanks to those contributors as well as to the peer reviewers who so generously gave of their time and expertise. The diligent contribution of peer reviewers to published research is often a rather thankless task, but without the rigour of their engagement, their field-specific expertise and judgment, and generous suggestions and recommendations, the editor's task would be an impossible one.

Nigel McLoughlin is Professor of Creativity \& Poetics at the University of Gloucestershire, UK. He is a prize-winning Northern Irish poet, editor and teacher. He is the author of five collections of poetry, the latest of which is Chora: New \& Selected Poems (Templar Poetry 2009). Since 2008, he has been Editor of Iota poetry journal. In 2002, he co-edited Breaking The Skin, an anthology of new Irish writing. He also edits the journal Creative Writing: Teaching Theory and Practice www.cwteaching.com. Sample recordings of his poems can be found on his website: www.nigelmcloughlin.co.uk.

Donna Lee Brien is Professor of Creative Industries and Associate Dean, Research and Postgraduate, in the School of Creative and Performing Arts at Central Queensland University, Australia, and Special Issues Editor of TEXT. 